\title{
Coordinating a supply chain under demand and cost disruptions
}

\author{
Erbao Cao, Xiushuai Zhou \& Kevin L\#
}

To cite this article: Erbao Cao, Xiushuai Zhou \& Kevin L\# (2015) Coordinating a supply chain under demand and cost disruptions, International Journal of Production Research, 53:12, 3735-3752, DOI: $10.1080 / 00207543.2014 .988885$

To link to this article: http://dx.doi.org/10.1080/00207543.2014.988885

曲 Published online: 15 Dec 2014.

Submit your article to this journal $\sqsubset x$

Џ Article views: 210

Q View related articles $₫$

View Crossmark data ¿ 


\title{
Coordinating a supply chain under demand and cost disruptions
}

\author{
Erbao $\mathrm{Cao}^{\mathrm{a}, \mathrm{b}}$, Xiushuai Zhou ${ }^{\mathrm{a}}$ and Kevin Lö ${ }^{\mathrm{c} *}$ \\ ${ }^{a}$ College of Economics and Trade, Hunan University, Changsha, China; ${ }^{b}$ Department of Industrial and Enterprise Systems Engineering, \\ University of Illinois at Urbana-Champaign, Urbana, IL, USA; ${ }^{c}$ Brunel Business School, Brunel University, Uxbridge, UK
}

(Received 5 August 2013; accepted 8 November 2014)

\begin{abstract}
In this paper, we investigate the coordination of a supply chain consisting of one manufacturer and $n$ Bertrand competing retailers under disruptions of market demand and production cost. We present a coordination model of a supply chain under normal scenarios. Our findings demonstrate that the coordination scheme designed for the initial production plan should be revised when disruptions of market demand and production cost occur. To resolve this issue, we consider the possible deviation costs caused by disruptions and propose optimal decision models for different disruptions under centralised decision-making. We present an improved revenue-sharing contract model to coordinate the decentralised supply chain under disruptions. The proposed models are then further analysed through numerical examples.
\end{abstract}

Keywords: supply chain coordination; disruption management; decision support; revenue-sharing contract; game theory; optimisation

\section{Introduction}

In recent years, supply chain coordination has emerged as an attractive area for firms to improve performance (Cachon 2003). Existing studies on supply chain coordination have mainly focused on decision-making under a normal marketing environment, which assumes that the demand is deterministic and known, and the manufacturer has perfect information about the market demands and so on. However, as economic integration and globalisation deepen, the unexpected changes of market demands and production costs are more common than ever before (Lei, Li, and Liu 2012). After the production or sales plans have been agreed, the marketing environment can often be disrupted by unexpected haphazard events, which may result in changes in demand or the cost of the products that affect the original production or sales plans. Therefore, such demand and cost disruptions may have significant impacts on business performance since supply chains can hardly recover from these disruptions in a short period time if these disruptions are not managed properly. It would benefit to the members of a supply chain if effective strategies to deal with such disruptions have been adopted in order to attain supply chain performance.

Both academics and practitioners recognise the importance of an effective contract to deal with supply chain disruptions (Yu and Qi 2004; Wu et al. 2010). A number of models have been proposed in order to study how to handle supply chain disruptions (Qi, Bard, and Yu 2004; Xu, Qi, and Yu 2006; Xiao and Qi 2008). Adjusting and handling unexpected disruptions in an efficient and effective way are becoming more and more important to the success of supply chain management. However, previous studies on supply chain coordination management mainly focus on static coordination mechanisms, with quantity discount under a deterministic environment, such as known market demands and production costs (Cachon 2003). The situation of cost or demand disruptions in one supplier and one retailer supply chain have been considered (Qi, Bard, and Yu 2004; Yu and Qi 2004; Xu, Qi, and Yu 2006; Lei, Li, and Liu 2012). However, many manufacturers face multiple geographically dispersed and heterogeneous retailers (Yu and Qi 2004).

With considerations to more close to real world situations, this study investigates how disruptions would affect the coordination scheme with revenue-sharing contracts and how to coordinate the supply chain after disruptions. In particular, the study examines the scenario where production costs and demands disruptions occur at the same time. To the best of our knowledge, it is the first time that a revenue-sharing contract to coordinate a supply chain with multiple retailers under demand and cost simultaneous disruptions has been considered.

Production cost disruptions often refer to situations in which production costs change from their estimated values, which are used to design the coordination scheme. Cost disruptions may occur when raw material prices and transportation

\footnotetext{
*Corresponding author. Email: kevin.lu@brunel.ac.uk 
costs change, or due to equipment failures or interest rate fluctuations (Xu, Qi, and $\mathrm{Yu}$ 2006). Cost disruptions can occur in various forms at any stage of the production process with varying consequences. Thus, different solutions are needed for each of those situations. Unexpected changes in market demands are very common in practice (Qi, Bard, and Yu 2004), for example, an earthquake might cause a large sudden demand for tents; the epidemic of mad cow disease affected the demand for beef consumption to a large degree. Such costs or/and demand disruptions will impact on consumers, retailers, wholesalers and manufacturers in an entire supply chain; thus, effective models and coordination mechanisms for the supply chain are needed in order to handle such disruptions. To adopt optimised decisions to deal with disruptions from a systems point of view will provide the decision-makers distinctive advantages.

In this paper, we focus on the scenario that simultaneous production cost and demand disruptions occur in a supply chain, which includes a single manufacturer and $n$ retailers who compete in a Bertrand market. Our particular interest is supply chain coordination. It is assumed that the manufacturer first acts as a Stackelberg leader, who offers the retailers a take-it-or-leave-it contract menu, including different revenue-sharing contracts, and the retailers then act as the followers who will choose both how many units of the product to order and its retail price. In a centralised supply chain, the central decision-maker determines the retail price and the production quantity, aiming at supply chain profit maximisation under a disruption scenario. In the decentralised supply chain, the manufacturer and the retailers are independent decision-makers who seek to maximise their individual profit.

We analyse the managerial insights on how production cost and demand disruptions affect a revenue-sharing contract where there are competing retailers. We have some interesting observations: first, it is possible that the manufacturer's original production plan could tolerant a certain degree of disruptions and retain a certain degree of robustness; when the cost and demand are changed within certain thresholds, it is acceptable for the supply chain to keep the original production plan, and for adjustments in prices alone to compensate the deviation costs. Only when the change in the demand and cost exceed certain thresholds, should both the original production quantities and the prices be adjusted. Second, the disruptions may have a significant effect on the revenue-sharing contract, including the order quantities, wholesale prices and revenue share, so the improved revenue-sharing contract could coordinate the decentralised supply chain and produce greater profit than the scenario where the original plan is retained.

The remainder of the paper is organised as follows: the related literature is reviewed in Section 2. Section 3 introduces the basic coordination model. Section 4 presents the coordination of a centralised supply chain with revenuesharing contracts. In Section 5, the coordination of the decentralised supply chain with improved revenue-sharing contracts is introduced. Numerical examples with analytical results are presented in Section 6. Section 7 summarises this paper.

\section{Related work}

This study is related to the intersection of supply chain coordination and disruption management, and two elements in the arena of supply chain coordination management, namely the revenue-sharing contract, supply chain disruption management. Hence, in the following, recent studies on these topics are reviewed and analysed.

Designing coordination schemes have been an important issue in the study of supply chain management (Wu et al. 2010). A revenue-sharing contract is beneficial to manufacturers, retailers and other participants within a supply chain (Cachon and Lariviere 2005). In deterministic demand aspects, Giannoccaro and Pontrandolfo (2004) coordinated a three stage supply chain with a revenue-sharing contract. Kebing, Chengxiu, and Yan (2007) studied coordination mechanisms in a supply chain consisting of one supplier and multiple retailers under deterministic price-sensitive customer demand and developed a revenue-sharing contract to coordinate such a supply chain. In undeterministic demand aspects, Pasternack (1985) indicated that the right revenue-sharing contract can coordinate two dyadic supply chains under stochastic demand; Dana and Spier (2001) adopted revenue-sharing contracts to coordinate a supply chain in a basic supplier-retailer channel setting. Cachon and Lariviere (2005) generalised Dana and Spier (2001) by studying the revenue-sharing contract in a two-echelon distribution channel with competing retailers and found that in an extended setting, where market demand is both retail price sensitive and stochastic, only a revenue-sharing contract can coordinate the channel. Gerchak and Wang (2004) considered a revenue-sharing contract in assembly systems with random demand. Wang, Jiang, and Shen (2004) studied the channel performance of supply chains under consignment contract with revenue sharing and found that both the overall channel performance and the performance of individual firms depend critically on demand price elasticity and on the retailer's share of channel cost and indicate that a decentralised supply chain cannot be perfectly coordinated. Li and Hua (2008) extended the work of Wang et al. and provided a cooperative game model that implements profit sharing between the manufacturer and the retailer to achieve their cooperation. Weng (2004) also considered the revenue-sharing contract in a one-period, supplier-buyer channel facing uncertain and price-dependent market demand and found that the loss in channel profit increases with demand price elasticity and decreases with the buyer's share of cost. Zou, Pokharel, and Piplani (2004) developed an analytical model 
to synchronise different processing times through the strategic placement of safety stocks at each player's premise and found that a revenue-sharing contract can be used for channel coordination in a two-echelon decentralised assembly system facing uncertain market demand. In multi-retailer aspects, Yao, Leung, and Lai (2008) investigated a revenuesharing contract for coordinating a supply chain comprising one manufacturer and two competing retailers, they assumed the demand from two competing retailers is independent and all parties know their demand distributions at the beginning of the season, but they did not consider the situations of demand or cost disruptions. It was found that the provision of revenue sharing in the contract can provide better performance than a price-only contract.

Chen, Zhang, and Sun (2012) studied a manufacturer's pricing strategies in a dual-channel supply chain and found that a manufacturer's contract with a wholesale price and a price for the direct channel can coordinate the dual-channel supply chain. Cachon (2003) summarised supply chain coordination mechanisms and offered a detailed review on the strengths and limitations of different supply chain contracts.

Disruption management in the supply chain is another aspect closely related to our work. Supply chain disruption management has attracted increasing attention (Yu and Qi 2004; Wu et al. 2010). One main difference between coordination under disruptions and coordination under a normal environment is that the sudden changes in demands and costs will cause certain deviation costs that did not previously exist (Yu and Qi 2004). These deviation costs can be caused by the over-time production and the expedited delivery for an increased demand, or the extra inventory holding and possible disposal for a decreased demand. The costs may be incurred by either the manufacturer or the retailers. To achieve effective supply chain management, such deviation costs must be appropriately taken into account. The concept of disruption management was first introduced by Clausen, Hansen, and Larsen (2001) and applied successfully in airline operations. Xiao and Yu (2006) studied the effects of supply chain disruptions on the evolution of retailers' behaviour, where retailers are bounded rationality and quantity competition with homogeneous goods. All the above work assumed a centralised system without considering coordination schemes.

In demand disruption aspects, Qi, Bard, and Yu (2004) examined a scenario with one manufacturer and one retailer under demand disruptions and proposed a quantity discount contract to coordinate a two-stage supply chain. Huang, Yu, and Song (2006) studied an exponential demand disruption and adopted an all-quantity discount policy to coordinate a supply chain. Chen and Xiao (2009) developed two coordination models of a supply chain consisting of one manufacturer, one dominant retailer and multiple fringe retailers to investigate how to coordinate a supply chain after demand disruption. Zegordi and Davarzani (2012) used a Petrinets-based model as a tool to understand the dissemination of disruptions and to trace the operational performance of a supply chain. Chen and Zhuang (2011) considered a coordination model of a one manufacturer and multi-retailer supply chain with a dominant retailer's sales promotion opportunity and possible demand disruption. Huang, Yang, and Zhang (2012) studied the pricing and production problem in a two-period dual-channel supply chain consisting of one manufacturer and one retailer with demand disruptions.

In the cost disruption aspect, $\mathrm{Xu}, \mathrm{Qi}$, and $\mathrm{Yu}$ (2006) studied the case of production cost being disrupted and proposed a quantity discount contract to coordinate a supplier-retailer supply chain. Hou, Zeng, and Zhao (2010) proposed a buy-back contract between a buyer and a backup supplier when the buyer's main supplier experiences supply and demand disruptions. Li, Wang, and Cheng (2010) investigated the sourcing strategy of a retailer and the pricing strategies of two suppliers in a supply chain under an environment of supply disruption. Yu, Zeng, and Zhao (2009) evaluated the impacts of supply disruption risks on the choice between the famous single and dual sourcing methods in a two-stage supply chain with a non-stationary and price-sensitive demand. Friesz, Lee, and Lin (2011) presented a dynamic supply chain network framework formulated as a differential variational inequality model, which allows consideration of supply chain disruptions threat to producers, freight carriers and retail enterprises and resolved the differential variational inequality by adopting a fixed point algorithm.

Issues of demand and cost disruption happening simultaneously were addressed in Lei, Li, and Liu (2012), where risk management strategies in a supply chain were examined when the disruptions of demand and cost occurred. Xiao and Qi (2008) presented a quantity discount contract to coordinate the supply chain with two Bertrand completing retailers when production cost and market demand disruptions existed.

Wu et al. (2010) found that the linear quantity discount scheme can coordinate the supply chain with two competing retailers, and the all-unit quantity discount scheme can coordinate the supply chain if the retailers are identical after the market demand is disrupted. This study is mainly focused on the effects of demand disruption on the coordination mechanism with quantity discount.

Although the revenue-sharing contract has been proven to be effective to coordinate the supply chain, in the existing literature, the revenue-sharing contract has not been used in the study of supply chain coordination under demand and cost disruptions. In this paper, we analyse the effects of simultaneous demand and cost disruptions on a supply chain consisting of one manufacturer and $n$ Bertrand competing retailers and investigate how to coordinate such a supply chain with demand and cost simultaneous disruptions by a revenue-sharing contract. 


\section{The basic model}

We first consider the coordination mechanism of a supply chain in the baseline case (without disruption or under normal circumstances). We begin with a manufacturer and $n$ retailer model in which the price-demand relationship is deterministic and known. The manufacturer produces a product that is purchased by the retailers, who then sell it on the open market. The situation can be viewed as a Stackelberg game, with the manufacturer assuming the role of the leader and the retailers as the roles of the followers. In this context, the manufacturer plays first by offering the retailers a menu of contracts $\left\{\left(w_{i}, \phi_{i}\right)\right\}$, in which the contract $i$ is only a component contract, and each retailer $i$ is free to choose a component contract that is most preferred from the menu. The revenue-sharing contract $i$ includes the wholesale price $w_{i}$ and a share of revenue $\phi_{i}$ generated from each unit. The retailers act as followers then react to the menu of contracts by choosing their most preferred contracts and choose the ordering quantities and retail price. At the same time, it is assumed that the system information is perfect, that is, the individuals of a supply chain have the demand and cost information. Let $c_{s}$ be the manufacturer's unit production cost and $c_{r i}$ is the retailer $i$ unit production cost; thus, $c_{i}=c_{s}+c_{r i}$ is the total production cost of channel $i$ and suppose that the ordering quantity of retailer $i$ is described by the following relationship

$$
q_{i}=a_{i}-p_{i}+d \sum_{j \neq i} p_{j}
$$

the linear demand function is commonly used in the literatures of supply chain management (Bernstein and Federgruen 2003; Cachon and Lariviere 2005; Xiao and Qi 2008). Where $a_{i}$ is the market scale (i.e. the maximum possible demand), $p_{i}$ is the retail price (a decision variable). Similar to Xiao and Qi (2008), $0<d<\frac{1}{n-1}$ is the substitutability coefficient of products with different price. The substitutability coefficient $0<d<\frac{1}{n-1}$ is a measure of the sensitivity of the $i$ th retailer's sales to the change of the other retailers' price. When the suffixes $i$ and $j$ simultaneously emerge in an equation, it always means that $i, j=1,2, \ldots, n ; j \neq i$. Let $p_{-i}=p-p_{i}=\left(\sum_{i=1}^{n} p_{i}\right)-p_{i}$; then, the revenue of retailer $i$ can be represented as $R_{i}(p)=p_{i} \cdot\left(a_{i}-p_{i}+d p_{-i}\right)$. For simplicity, let $R_{i}^{i}(p)=\frac{\partial R_{i}(p)}{\partial p_{i}}$ and $R_{j}^{i}(p)=\frac{\partial R_{j}(p)}{\partial p_{i}}$. Similar to Cachon and Lariviere (2005), we assume that the retailer $i$ 's revenue is decreasing in $q_{i}$, that is $\frac{\partial R_{i}(q)}{\partial q_{i}}<0$. Therefore, the retailer $i$ 's revenue is increasing if retailer $i$ has increased the price $p_{i}$, that is, $R_{i}^{i}(p)=\frac{\partial R_{i}(p)}{\partial p_{i}}=\frac{\partial R_{i}(q)}{\partial q_{i}} \frac{\partial q_{i}}{\partial p_{i}}>0$. We further assume that the retailer $i$ 's revenue is also decreasing if retailer $j$ has increased the sales $q_{j}$, that is, $\frac{\partial R_{i}(q)}{\partial q_{j}}<0$, and the sales are substitute among the different retailers, that is, $\frac{\partial^{2} R_{i}(q)}{\partial q_{i} \partial q_{j}}<0$. This means that the retailer $i$ 's customers will transfer to other retailers if retailer $i$ has a shortage. Therefore, we have $R_{j}^{i}(p)=\frac{\partial R_{j}(p)}{\partial p_{i}}=\frac{\partial R_{j}(p)}{\partial q_{i}} \frac{\partial q_{i}}{\partial p_{i}}>0$. It is shown that the revenue of retailer $j$ is increasing (decreasing) with retailer $i$ 's retail price (sales) increase.

Let $\Pi_{i}(q)$ be the supply chain's profit made at channel $i, \Pi_{i}\left(p_{i}\right)=R_{i}(p)-c_{i} q_{i}$, and let $\Pi_{T}(p)$ be the supply chain system total profit:

$$
\Pi_{T}(p)=\sum_{i=1}^{n}\left[R_{i}(p)-c_{i} q_{i}\right]=\Pi_{i}+\sum_{j \neq i}^{n} \Pi_{j}=\left(p_{i}-c_{i}\right)\left(a_{i}-p_{i}+d \sum_{j \neq i}^{n} p_{j}\right)+\sum_{j \neq i}^{n}\left(p_{j}-c_{j}\right)\left(a_{j}-p_{j}+d \sum_{i \neq j}^{n} p_{i}\right)
$$

Clearly $\frac{\partial^{2} \Pi_{T}(p)}{\partial p_{i}{ }^{2}}<0$, therefore, the supply chain system total profit is a concave function about the retail price. Denoting a system optimal vector of quantities and retail prices as $q^{0}=\left(q_{1}^{0}, q_{2}^{0}, \ldots, q_{n}^{0}\right), p^{0}=\left(p_{1}^{0}, p_{2}^{0}, \ldots, p_{n}^{0}\right)$, respectively, then $p^{0}$ satisfies the following first-order conditions $\frac{\partial \Pi_{T}(p)}{\partial p_{i}}=a_{i}-p_{i}+d \sum_{j \neq i}^{n} p_{j}-\left(p_{i}-c_{i}\right)+d \sum_{j \neq i}^{n}\left(p_{j}-c_{j}\right)=0$, $i=1,2, \ldots, n$, accordingly, we have $2 p_{i}=a_{i}+d \sum_{j \neq i}^{n}\left(2 p_{j}-c_{j}\right)+c_{i}$. The equilibrium retail prices of the $n$ retailers can be found by solving simultaneously the $n$ equations, the summation of retail prices is

$$
\underline{P^{0}}=\frac{\sum_{i=1}^{n}\left[a_{i}+(1-(n-1) d) c_{i}\right]}{2[1-(n-1) d]}
$$

(because of $0<d<\frac{1}{n-1}, \underline{P^{0}}>0$ ), the $n$ retailers determine their retail prices simultaneously, and their retail prices are the following unique Nash-Equilibrium point: 


$$
\begin{aligned}
& p_{i}^{0}=\frac{1}{2(1+d)} \cdot\left\{a_{i}+(1+d) c_{i}-d \sum_{i=1}^{n} c_{i}+d \cdot \frac{\sum_{i=1}^{n}\left[a_{i}+(1-(n-1) d) c_{i}\right]}{1-(n-1) d}\right\}, \quad i=1,2, \ldots, n . \\
& q_{i}^{0}=a_{i}-p_{i}^{0}+d \sum_{j \neq i} p_{j}^{0}
\end{aligned}
$$

In a decentralised supply chain system, the manufacturer offers the retailers a revenue-sharing contract menu $\left\{\left(w_{i}, \phi_{i}\right)\right\}$, and retailer $i$ determines optimal retail price $p_{i}$ aiming to maximise its own profit given the contractual terms, it is assumed that each retailer makes its decision independently. Consequently, retailer $i$ 's profit would be $\Pi_{r i}=\phi_{i} R_{i}-\left(w_{i}+c_{r i}\right) q_{i}$, and the manufacturer's profit from channel $i$ is $\Pi_{s i}=\left(1-\phi_{i}\right) R_{i}+\left(w_{i}-c_{s}\right) q_{i}$.

The following theorem indicates that the manufacturer can use the revenue-sharing contract to induce the retail prices to $p_{i}^{0}$ and order quantity to $q_{i}^{0}$. As a consequence, the manufacturer's own goal and maximum supply chain profit can be achieved.

Proposition 1. The following revenue-sharing contracts coordinate a supply chain with Bertrand competing retailers, if the contractual terms $\left(w_{i}, \phi_{i}\right)$ satisfy the equation $w_{i}^{0}=\phi_{i}^{0}\left(2 p_{i}^{0}-a_{i}-d \sum_{j \neq i}^{n} p_{j}^{0}\right)-c_{r i} \quad$ and $\max \left(\frac{\left(\overline{p_{i}^{0}}-\overline{w_{i}^{0}}-c_{r i}\right) \overline{q_{i}^{0}}}{\left(a_{i}+d \sum_{j \neq i} p_{j}^{0}-p_{i}^{0}\right) q_{i}^{0}}, \frac{c_{r i}+c_{s}}{2 p_{i}^{0}-a_{i}-d \sum_{j \neq i}^{n} p_{j}^{0}}\right)<\phi_{i}^{0}<1, \sum_{i=1}^{n}\left[\phi_{i}^{0}\left(p_{i}^{0}-a_{i}-d \sum_{j \neq i}^{n} p_{j}^{0}\right)+p_{i}^{0}-c_{r i}-c_{s}\right] q_{i}^{0}>\sum_{i=1}^{n}\left(\overline{w_{i}^{0}}-c_{s}\right) \overline{q_{i}^{0}}$, $i=1,2, \ldots, n$. The optimal profits of the retailer and the manufacturer in channel $i$ is

$$
\begin{gathered}
\Pi_{r i}\left(p^{0}\right)=\phi_{i} \cdot\left[\Pi_{i}\left(p^{0}\right)+q_{i}^{0} \sum_{j \neq i}^{n} \Pi_{j}^{i}\left(p^{0}\right)\right] \\
\Pi_{s i}\left(p^{0}\right)=\left(1-\phi_{i}\right) \cdot\left[\Pi_{i}\left(p^{0}\right)+q_{i}^{0} \sum_{j \neq i}^{n} \Pi_{j}^{i}\left(p^{0}\right)\right]-q_{i}^{0} \sum_{j \neq i}^{n} \Pi_{j}^{i}\left(p^{0}\right), \quad i=1,2, \ldots, n ; j \neq i
\end{gathered}
$$

Proof: The supply chain system total profit is

$$
\Pi_{T}(p)=\sum_{i=1}^{n}\left[R_{i}(p)-c_{i} q_{i}\right]=\Pi_{i}+\sum_{j \neq i}^{n} \Pi_{j}=\left(p_{i}-c_{i}\right)\left(a_{i}-p_{i}+d \sum_{j \neq i}^{n} p_{j}\right)+\sum_{j \neq i}^{n}\left(p_{j}-c_{j}\right)\left(a_{j}-p_{j}+d \sum_{i \neq j}^{n} p_{i}\right)
$$

and the optimal retail price of a supply chain system must meet the following first-order condition:

$$
\frac{\partial \Pi_{T}(p)}{\partial p_{i}}=\frac{\partial \Pi_{i}}{\partial p_{i}}+\frac{\partial\left(\sum_{j \neq i}^{n} \Pi_{j}\right)}{\partial p_{i}} \triangleq \Pi_{i}^{i}+\sum_{j \neq i}^{n} \Pi_{j}^{i}=a_{i}-p_{i}+d \sum_{j \neq i}^{n} p_{j}-\left(p_{i}-c_{i}\right)+d \sum_{j \neq i}^{n}\left(p_{j}-c_{j}\right)=0 ;
$$

then we can get

$$
\begin{gathered}
p_{i}^{0}=\frac{1}{2(1+d)} \cdot\left\{a_{i}+(1+d) c_{i}-d \sum_{i=1}^{n} c_{i}+d \cdot \frac{\sum_{i=1}^{n}\left[a_{i}+(1-(n-1) d) c_{i}\right]}{1-(n-1) d}\right\}, \quad i=1,2, \ldots, n . \\
q_{i}^{0}=a_{i}-p_{i}^{0}+d \sum_{j \neq i} p_{j}^{0}
\end{gathered}
$$

the profit of retailer $i$ is

$$
\Pi_{r i}=\phi_{i} R_{i}-\left(w_{i}+c_{r i}\right) q_{i}=\phi_{i} p_{i}\left(a_{i}-p_{i}+d \sum_{j \neq i}^{n} p_{j}\right)-\left(w_{i}+c_{r i}\right)\left(a_{i}-p_{i}+d \sum_{j \neq i}^{n} p_{j}\right),
$$


the optimal retail prices that the retailers decided must meet the following first-order condition $\frac{\partial \Pi_{r i}}{\partial p_{i}}=\phi_{i}\left(a_{i}-p_{i}+d \sum_{j \neq i}^{n} p_{j}-p_{i}\right)+\left(w_{i}+c_{r i}\right)=0$; if the revenue-sharing contract $\left(w_{i}, \phi_{i}\right)$ can coordinate the supply chain, then the optimal retail prices that retailers decided must equal to that of a supply chain, $p_{i}=p_{i}^{0}$, therefore the following equation must hold:

$$
w_{i}^{0}=\phi_{i}^{0}\left(2 p_{i}^{0}-a_{i}-d \sum_{j \neq i}^{n} p_{j}^{0}\right)-c_{r i}
$$

Because $0<\phi_{i}^{0}<1$ and it is illegal to sell below cost in practice (i.e. $w_{i}^{0}>c_{s}$ ), the retailer's revenue share should satisfy $\frac{c_{r i}+c_{s}}{2 p_{i}^{0}-a_{i}-d \sum_{j \neq i}^{n} p_{j}^{0}}<\phi_{i}^{0}<1$.

Then the profits of the retailer and manufacture are as below

$$
\begin{gathered}
\prod_{r i}^{0}=\left(\phi_{i}^{0} p_{i}^{0}-w_{i}^{0}-c_{r i}\right) q_{i}^{0} \\
\prod_{s}^{0}=\sum_{i=1}^{n}\left(\left(1-\phi_{i}^{0}\right) p_{i}^{0}+w_{i}^{0}-c_{s}\right) q_{i}^{0}
\end{gathered}
$$

At the same time, if the supply chain does not adopt the revenue-sharing contract in decentralised decisions, the profits of the partners can be listed as follows

$$
\begin{gathered}
\prod_{r i}=\left(p_{i}-w_{i}-c_{r i}\right) q_{i} \\
\prod_{s}=\sum_{i=1}^{n}\left(w_{i}-c_{s}\right) q_{i}
\end{gathered}
$$

From the first-order condition of retailer's profit $\frac{\partial \prod_{r i}}{\partial p_{i}}=\left(a_{i}-p_{i}+d \sum_{j \neq i}^{n} p_{j}\right)-p_{i}+\left(w_{i}+c_{r i}\right)=0$, we have $2 p_{i}=a_{i}+d \sum_{j \neq i}^{n} p_{j}+w_{i}+c_{r i}$. So the optimal price of retailer $i$ is $p_{i}=\frac{1}{2+d}\left(a_{i}+w_{i}+c_{r i}+d \cdot \frac{\sum_{i=1}^{n}\left(a_{i}+w_{i}+c_{r i}\right)}{2-(n-1) d}\right)$.

We substitute $p_{i}$ into $\prod_{s}=\sum_{i=1}^{n}\left(w_{i}-c_{s}\right) q_{i}$ and obtain the optimal wholesale price $\overline{w_{i}^{0}}$.
Basically, we have

$$
\begin{gathered}
\overline{p_{i}^{0}}=\frac{1}{2+d}\left(a_{i}+\overline{w_{i}^{0}}+c_{r i}+d \cdot \frac{\sum_{i=1}^{n}\left(a_{i}+\overline{w_{i}^{0}}+c_{r i}\right)}{2-(n-1) d}\right) \\
\overline{q_{i}^{0}}=a_{i}-\overline{p_{i}^{0}}+d \sum_{j \neq i}^{n} \overline{p_{j}^{0}} \\
\overline{\prod_{r i}^{0}}=\left(\overline{p_{i}^{0}}-\overline{w_{i}^{0}}-c_{r i}\right) \overline{q_{i}^{0}} \\
\overline{\prod_{s}^{0}}=\sum_{i=1}^{n}\left(\overline{w_{i}^{0}}-c_{s}\right) \overline{q_{i}^{0}}
\end{gathered}
$$


Further, we know that the revenue-sharing contracts are acceptable to the chain partners only if $\prod_{r i}^{0}>\overline{\prod_{r i}^{0}}$ and $\prod_{s}^{0}>\overline{\prod_{s}^{0}}$. Then we have $\phi_{i}^{0}>\frac{\left(\overline{p_{i}^{0}}-\overline{w_{i}^{0}}-c_{r i}\right) \overline{q_{i}^{0}}}{\left(a_{i}+d \sum_{j \neq i} p_{j}^{0}-p_{i}^{0}\right) q_{i}^{0}}$

$$
\sum_{i=1}^{n}\left[\phi_{i}^{0}\left(p_{i}^{0}-a_{i}-d \sum_{j \neq i}^{n} p_{j}^{0}\right)+p_{i}^{0}-c_{r i}-c_{s}\right] q_{i}^{0}>\sum_{i=1}^{n}\left(\overline{w_{i}^{0}}-c_{s}\right) \overline{q_{i}^{0}}
$$

Clearly, the partners of the supply chain can obtain non-negative profit, and the revenue-sharing contract $\left(w_{i}, \phi_{i}\right)$ can effectively coordinate the supply chain with $n$ Bertrand competing retailers.

\section{Centralised decisions with disruptions}

In a centralised supply chain system, the manufacturer and the retailers are vertically integrated in a supply chain, they seek to maximise the total system profit of a supply chain after the demand and costs disruptions have occurred. We consider the situation with simultaneous demand and cost disruptions. Suppose that the demand market scale changes from $a_{i}$ to $a_{i}+\Delta a_{i}$, and the manufacturer's production cost changes from $c_{s}$ to $c_{s}+\Delta c$. The ordering quantity of retailer $i$ is $\overline{q_{i}}=a_{i}+\Delta a_{i}-p_{i}+d \sum_{j \neq i}^{n} p_{j}$.

Further, we assume $a_{i}+\Delta a_{i}>p_{i}-d \sum_{j \neq i}^{n} p_{j}, c_{s}+\Delta c>0$. Let $q_{i}$ be the real demand of retailer $i$ under the disruptions and $\Delta q=\sum_{i=1}^{n}\left(q_{i}-q_{i}{ }^{0}\right)$ be the corresponding deviation of the manufacturer. When $\Delta q=\sum_{i=1}^{n}\left(q_{i}-q_{i}{ }^{0}\right)>0$, the production must be increased in order to meet the new market demand. Usually, the unit production cost for the additional products will be higher than the normal unit production cost because it has to get some extra production resources at a higher price. When $\Delta q=\sum_{i=1}^{n}\left(q_{i}-q_{i}{ }^{0}\right)<0$, there will be excess inventory that has to be sold in a secondary market at a low price (Xu, Qi, and Yu 2006; Wu et al. 2010). In both cases, the demand and cost disruptions will cause adjustments to the original production plan and ultimately affect the whole supply chain. We assume that the manufacturer bears fully the production deviation cost caused by the disruptions (Yu and Qi 2004; Qi, Bard, and Yu 2004; Xu, Qi, and Yu 2006; Xiao and Qi 2008; Lei, Li, and Liu 2012). To reflect the influence of production variance at each channel on the system total production deviation cost. It is further assumed that the manufacturer's production deviation cost will be determined by the weighted sum of each channel's production deviation cost. The weight of each channel is calculated as $\frac{1}{n}$. Note that the above assumptions are similar to those in the literatures (Qi, Bard, and Yu 2004; Xu, Qi, and Yu 2006; $\mathrm{Wu}$ et al. 2010). Therefore, the revenue and profit of location $i$ after disruptions can be calculated as, respectively:

$$
\begin{gathered}
\overline{R_{i}}=\left(a_{i}+\Delta a_{i}-p_{i}+d \sum_{j \neq i}^{n} p_{j}\right) p_{i}, \\
\overline{\Pi_{i}}=\left(a_{i}+\Delta a_{i}-p_{i}+d \sum_{j \neq i}^{n} p_{j}\right) p_{i}-\left(c_{i}+\Delta c\right) q_{i}-\frac{1}{n}\left[m_{1} \cdot\left(\sum_{i=1}^{n} q_{i}-\sum_{i=1}^{n} q_{i}^{0}\right)^{+}+m_{2} \cdot\left(\sum_{i=1}^{n} q_{i}^{0}-\sum_{i=1}^{n} q_{i}\right)^{+}\right],
\end{gathered}
$$

and the total supply chain system profit is

$$
\begin{aligned}
\overline{\Pi_{T}}(p) & =\sum_{i=1}^{n} \bar{\Pi}_{i} \\
& =\sum_{i=1}^{n}\left\{\left(a_{i}+\Delta a_{i}-p_{i}+d \sum_{j \neq i}^{n} p_{j}\right) \cdot\left(p_{i}-c_{i}-\Delta c\right)-\frac{1}{n}\left[m_{1} \cdot\left(\sum_{i=1}^{n} q_{i}-\sum_{i=1}^{n} q_{i}^{0}\right)^{+}+m_{2} \cdot\left(\sum_{i=1}^{n} q_{i}^{0}-\sum_{i=1}^{n} q_{i}\right)^{+}\right]\right\} \\
& =\sum_{i=1}^{n}\left[\left(a_{i}+\Delta a_{i}-p_{i}+d \sum_{j \neq i} p_{j}\right)\left(p_{i}-c_{i}-\Delta c\right)\right]-m_{1} \cdot\left(\sum_{i=1}^{n} q_{i}-\sum_{i=1}^{n} q_{i}^{0}\right)^{+}-m_{2} \cdot\left(\sum_{i=1}^{n} q_{i}^{0}-\sum_{i=1}^{n} q_{i}\right)^{+}
\end{aligned}
$$




$$
\begin{aligned}
= & \left(a_{i}+\Delta a_{i}-p_{i}+d \sum_{j \neq i} p_{j}\right)\left(p_{i}-c_{i}-\Delta c\right)+\sum_{j \neq i}^{n}\left(a_{j}+\Delta a_{j}-p_{j}+d \sum_{i \neq j} p_{i}\right)\left(p_{j}-c_{j}-\Delta c\right)-m_{1} \\
& \cdot\left(\sum_{i=1}^{n}\left(a_{i}+\Delta a_{i}-p_{i}+d \sum_{j \neq i} p_{j}\right)-\sum_{i=1}^{n} q_{i}^{0}\right)^{+}-m_{2} \cdot\left(\sum_{i=1}^{n} q_{i}^{0}-\sum_{i=1}^{n}\left(a_{i}+\Delta a_{i}-p_{i}+d \sum_{j \neq i} p_{j}\right)\right)^{+}
\end{aligned}
$$

where $(x)^{+}=\max \{0, x\}, m_{1}>0, m_{2}>0$ are the marginal extra costs of increased or decreased production from the original plan, respectively. $m_{1}>0$ is the unit extra production cost compared with what has been planned when $\Delta q>0$, and $m_{2}>0$ is the unit cost of handling the leftover inventory when the actual demand is inferior to the original plan, $\Delta q<0$ (see (Xiao, Yu, and Sheng 2005; Xu, Qi, and Yu 2006)). If there is a centralised decision-maker who tries to maximise the total supply chain system profit $\overline{\Pi_{T}}(p)$, the decision-maker will find the optimal retail price $p^{*}=\left(p_{1}^{*}, p_{2}^{*}, \ldots, p_{n}^{*}\right)$ that maximises Equation (3) and the corresponding optimal order quantity $q^{*}=\left(q_{1}^{*}, q_{2}^{*}, \ldots, q_{n}^{*}\right)$. Intuitively, when the production cost increases or demand decreases, the optimal order quantity should decrease and vice versa. We discuss the retailer's price decision by comparing the production quantity before and after disruptions.

When $\sum_{i=1}^{n} \Delta a_{i} \geq \sum_{i=1}^{n}\left(q_{i}^{0}-a_{i}+p_{i}-d \sum_{j \neq i}^{n} p_{j}\right)$, the problem of maximising $\overline{\Pi_{T}}(p)$ reduces to maximising the following strictly concave function:

$$
\begin{aligned}
\overline{\Pi_{T 1}}\left(p_{i}\right)= & \left(a_{i}+\Delta a_{i}-p_{i}+d \sum_{j \neq i} p_{j}\right)\left(p_{i}-c_{i}-\Delta c\right)+\sum_{j \neq i}^{n}\left(a_{j}+\Delta a_{j}-p_{j}+d \sum_{i \neq j} p_{i}\right)\left(p_{j}-c_{j}-\Delta c\right)-m_{1} \\
& \cdot\left[\sum_{i=1}^{n}\left(a_{i}+\Delta a_{i}-p_{i}+d \sum_{j \neq i} p_{j}\right)-\sum_{i=1}^{n} q_{i}^{0}\right]
\end{aligned}
$$

and when $\sum_{i=1}^{n} \Delta a_{i} \leq \sum_{i=1}^{n}\left(q_{i}^{0}-a_{i}+p_{i}-d \sum_{j \neq i}^{n} p_{j}\right)$, the problem of maximising $\overline{\Pi_{T}}(p)$ reduces to maximising the following strictly concave function:

$$
\begin{aligned}
\overline{\Pi_{T 2}}\left(p_{i}\right)= & \left(a_{i}+\Delta a_{i}-p_{i}+d \sum_{j \neq i} p_{j}\right)\left(p_{i}-c_{i}-\Delta c\right)+\sum_{j \neq i}^{n}\left(a_{j}+\Delta a_{j}-p_{j}+d \sum_{i \neq j} p_{i}\right)\left(p_{j}-c_{j}-\Delta c\right)-m_{2} \\
& \cdot\left[\sum_{i=1}^{n} q_{i}^{0}-\sum_{i=1}^{n}\left(a_{i}+\Delta a_{i}-p_{i}+d \sum_{j \neq i} p_{j}\right)\right]
\end{aligned}
$$

The Kuhn-Tucker condition of Equation (4) is that at the optimal retail prices $p^{*}=\left(p_{1}^{*}, p_{2}^{*}, \ldots, p_{n}^{*}\right)$ and ordering quantity $q^{*}=\left(q_{1}^{*}, q_{2}^{*}, \ldots q_{n}^{*}\right)$, there exists a Lagrangian multiplier $\lambda \geq 0$ such that

$$
\left\{\begin{array}{l}
\frac{\partial \overline{\Pi_{T 1}}\left(p_{i}\right)}{\partial p_{i}}-\lambda=0 ; \quad i=1,2, \ldots, n \\
a_{i}+\Delta a_{i}-p_{i}+d \sum_{j \neq i}^{n} p_{j}--_{i}^{0} \geq 0 \\
\lambda\left(a_{i}+\Delta a_{i}-p_{i}+d \sum_{j \neq i}^{n} p_{j}-q_{i}^{0}\right)=0
\end{array}\right.
$$

To resolve the Kuhn-Tucker condition, we have two different cases with respect to the Lagrangian multiplier $\lambda=0$ or $\lambda>0$.

Case 1: when $\lambda=0$, then Equation (6) equivalent to $\frac{\partial \overline{\Pi_{T 1}}\left(p_{i}\right)}{\partial p_{i}}=0$ and $a_{i}+\Delta a_{i}-p_{i}+d \sum_{j \neq i}^{n} p_{j}-q_{i}^{0}>0$ hold simulta-

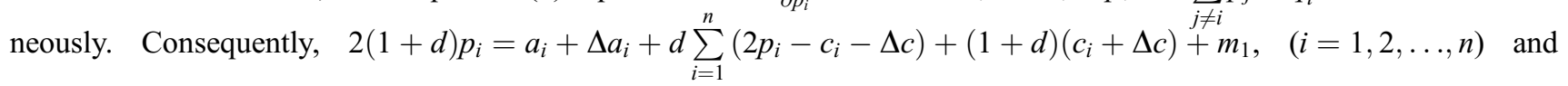
$a_{i}+\Delta a_{i}-p_{i}+d \sum_{j \neq i}^{n} p_{j}-q_{i}^{0}>0$ hold simultaneously. We obtain the total retail prices of retailers by accumulated adding 
thenequations, $\underline{P^{*}}=\frac{\sum_{i=1}^{n}\left[a_{i}+\Delta a_{i}+(1-(n-1) d)\left(c_{i}+\Delta c\right)\right]+n m_{1}}{2[1-(n-1) d]}$, thus we obtain the equilibrium retail prices of the $n$ retailers by solving the $n$ simultaneous equations, the optimal retail price of retailer $i$ is

$$
\begin{aligned}
p_{i}^{*}= & \frac{1}{2(1+d)} \\
& \cdot\left\{\begin{array}{l}
\left\{a_{i}+\Delta a_{i}-d \sum_{i=1}^{n}\left(c_{i}+\Delta c_{i}\right)+(1+d)\left(c_{i}+\Delta c\right)+m_{1}+2 d \cdot \frac{\sum_{i=1}^{n}\left[a_{i}+\Delta a_{i}+(1-(n-1) d)\left(c_{i}+\Delta c\right)\right]+n m_{1}}{2[1-(n-1) d]}\right\} \\
\quad=p_{i}{ }^{0}+\frac{1}{2(1+d)} \cdot\left\{\Delta a_{i}+(1-(n-1) d) \Delta c+m_{1}+d \cdot \frac{\sum_{i=1}^{n}\left[\Delta a_{i}+(1-(n-1) d) \Delta c\right]+n m_{1}}{1-(n-1) d}\right\},
\end{array}\right.
\end{aligned}
$$

and the constraint condition $a_{i}+\Delta a_{i}-p_{i}+d \sum_{j \neq i}^{n} p_{j}-q_{i}^{0}>0$ in Equation (6) is equivalent to the following inequality $\Delta c-\frac{\sum_{i=1}^{n} \Delta a_{i}}{n[1-(n-1) d]}<-\frac{m_{1}}{1-(n-1) d}$. Obviously, the optimal ordering quantity of retailer $i$ satisfies $q_{i}^{*}>q_{i}^{0}$.

Case 2: If $\lambda>0$, then the Kuhn-Tucker condition of Equation (6) equivalent to $\frac{\partial \overline{\Pi_{T 1}}\left(p_{i}\right)}{\partial p_{i}}=\lambda$ and $a_{i}+\Delta a_{i}-p_{i}+d \sum_{j \neq i}^{n} p_{j}-q_{i}^{0}=0 \quad$ hold $\quad$ simultaneously. $\quad$ Thus, $\quad 2(1+d) p_{i}=a_{i}+\Delta a_{i}+d \sum_{i=1}^{n}\left(2 p_{i}-c_{i}-\Delta c\right)+$ $(1+d)\left(c_{i}+\Delta c\right)+m_{1}-\lambda$ and $a_{i}+\Delta a_{i}-p_{i}+d \sum_{j \neq i}^{n} p_{j}-q_{i}^{0}=0$ hold simultaneously. The total retail prices of retailers can be obtained through accumulated adding of the nequations, the summation of retail prices is $\underline{P^{*}}=\frac{\sum_{i=1}^{n} \Delta a_{i}}{1-(n-1) d}+\underline{P^{0}}$. Thus, the optimal retail price for retailer $i$ is $p_{i}{ }^{*}=\frac{1}{(1+d)}\left[\Delta a_{i}+d \frac{\sum_{i=1}^{n} \Delta a_{i}}{1-(n-1) d}\right]+p_{i}{ }^{0}$, and the optimal ordering quantity of retailer $i$ is $q_{i}^{*}=q_{i}^{0}$. The constraint condition $\lambda>0$ is equivalent to $\lambda=a_{i}+\Delta a_{i}+d \sum_{i=1}^{n}\left(2 p_{i}-c_{i}-\Delta c\right)+(1+d)\left(c_{i}+\Delta c\right)+m_{1}-2(1+d) p_{i}>0$. Adding all the $n$ equations about $\lambda$ together then substituting $\underline{P^{*}}=\frac{\sum_{i=1}^{n} \Delta a_{i}}{1-(n-1) d}+\underline{P^{0}}=\frac{2 \sum_{i=1}^{n} \Delta a_{i}+\sum_{i=1}^{n}\left[a_{i}+(1-(n-1) d) c_{i}\right]}{2[1-(n-1) d]}$ into it, the constraint condition becomes the following inequality: $\lambda=[1-(n-1) d] \Delta c-\frac{\sum_{i=1}^{n} \Delta a_{i}}{n}+m_{1}>0$, which equals $\Delta c-\frac{\sum_{i=1}^{n} \Delta a_{i}}{n[1-(n-1) d]}>-\frac{m_{1}}{1-(n-1) d}$.

The Kuhn-Tucker condition of Equation (5) is that at the optimal retail prices $p^{*}=\left(p_{1}^{*}, p_{2}^{*}, \ldots, p_{n}^{*}\right)$, there exists a Lagrangian multiplier $u \geq 0$ such that the following equations hold

$$
\left\{\begin{array}{l}
\frac{\partial \overline{\Pi_{T 2}}\left(p_{i}\right)}{\partial p_{i}}+u=0 ; \quad i=1,2, \ldots, n \\
q_{i}^{0}-\left(a_{i}+\Delta a_{i}-p_{i}+d \sum_{j \neq i}^{n} p_{j}\right) \geq 0 \\
u q_{i}^{0}-\left(a_{i}+\Delta a_{i}-p_{i}+d \sum_{j \neq i}^{n} p_{j}\right)=0
\end{array}\right.
$$


Through resolving the Kuhn-Tucker condition, we have two different cases with respect to the Lagrangian multiplier $u$.

Case 3: when $u=0$, Equation (7) equivalent to $2(1+d) p_{i}=a_{i}+\Delta a_{i}+d \sum_{i=1}^{n}\left(2 p_{i}-c_{i}-\Delta c\right)+(1+d)$ $\left(c_{i}+\Delta c\right)-m_{2}$ and $q_{i}^{0}-\left(a_{i}+\Delta a_{i}-p_{i}+d \sum_{j \neq i}^{n} p_{j}\right)>0$ hold simultaneously. The summation of retail prices is $\underline{P^{*}}=\frac{\sum_{i=1}^{n}\left[a_{i}+\Delta a_{i}+(1-(n-1) d)\left(c_{i}+\Delta c\right)\right]-n m_{2}}{2[1-(n-1) d]}$, and then, the retail price of the $i$ th retailer can be found by

$$
\begin{aligned}
p_{i}^{*}= & \frac{1}{2(1+d)} \\
& \cdot\left\{a_{i}+\Delta a_{i}-d \sum_{i=1}^{n}\left(c_{i}+\Delta c_{i}\right)+(1+d)\left(c_{i}+\Delta c\right)-m_{2}+2 d \cdot \frac{\sum_{i=1}^{n}\left[a_{i}+\Delta a_{i}+(1-(n-1) d)\left(c_{i}+\Delta c\right)\right]-n m_{2}}{2[1-(n-1) d]}\right\} \\
\quad=p_{i}{ }^{0}+\frac{1}{2(1+d)} \cdot\left\{\Delta a_{i}+(1-(n-1) d) \Delta c-m_{2}+d \cdot \frac{\sum_{i=1}^{n}\left[\Delta a_{i}+(1-(n-1) d) \Delta c\right]-n m_{2}}{1-(n-1) d}\right\} &
\end{aligned}
$$

The constraint condition $a_{i}+\Delta a_{i}-p_{i}+d \sum_{j \neq i}^{n} p_{j}-q_{i}^{0}>0$ is equivalent to the following inequality $\Delta c-\frac{\sum_{i=1} \Delta a_{i}}{n[1-(n-1) d]}>\frac{m_{2}}{1-(n-1) d}$. Obviously, the optimal ordering quantity of retailer $i$ satisfies $q_{i}^{*}<q_{i}^{0}$.

Case 4: when $u>0$, the Kuhn-Tucker condition of Equation (7) equivalent to $2(1+d) p_{i}=a_{i}+\Delta a_{i}+d \sum_{i=1}^{n}\left(2 p_{i}-c_{i}-\Delta c\right)+(1+d)\left(c_{i}+\Delta c\right)-m_{2}+u \quad$ and $\quad q_{i}^{0}-\left(a_{i}+\Delta a_{i}-p_{i}+d \sum_{j \neq i}^{n} p_{j}\right)=0$ hold simultaneously, the total retail prices of retailers $\underline{P^{*}}=\frac{\sum_{i=1}^{n} \Delta a_{i}}{1-(n-1) d}+\underline{P^{0}}$, and the retail prices of retailer $i$ is $p_{i}{ }^{*}=\frac{1}{(1+d)}\left[\Delta a_{i}+d \frac{\sum_{i=1}^{n} \Delta a_{i}}{1-(n-1) d}\right]+p_{i}{ }^{0}$, and the optimal ordering quantity of retailer $i$ is $q_{i}^{*}=q_{i}^{0}$.

The constraint condition becomes $u=\frac{\sum_{i=1}^{n} \Delta a_{i}}{n}-[1-(n-1) d] \Delta c+m_{2}>0$, equivalent to $\Delta c-\frac{\sum_{i=1}^{n} \Delta a_{i}}{n[1-(n-1) d]}$ $<\frac{m_{2}}{1-(n-1) d}$.

Summarising the above results, we have the following proposition:

Proposition 2. When the Bertrand competing retailers' demand-price relationships satisfy $q_{i}=a_{i}-p_{i}+d \sum_{j \neq i} p_{j}$, the production cost disruption $\Delta c$ and market demand scale disruption $\Delta a_{i}$, the total supply chain profit is maximised at the optimal retail prices $p_{i}{ }^{*}$.

$$
\begin{aligned}
& p_{i}^{*}= \begin{cases}p_{i}^{0}+\frac{1}{2(1+d)}\left[\Delta a_{i}+(1-(n-1) d) \Delta c+m_{1}+K_{1}\right] & \text { if } \quad \frac{\sum_{i=1}^{n} \Delta a_{i}}{n[1-(n-1) d]}>\Delta c+\frac{m_{1}}{1-(n-1) d} \\
p_{i}^{0}+\frac{1}{(1+d)}\left[\Delta a_{i}+d \frac{\sum_{i=1}^{n} \Delta a_{i}}{1-(n-1) d}\right] & \text { if } \Delta c-\frac{m_{2}}{1-(n-1) d}<\frac{\sum_{i=1}^{n} \Delta a_{i}}{n[1-(n-1) d]}<\Delta c+\frac{m_{1}}{1-(n-1) d}, \\
p_{i}^{0}+\frac{1}{2(1+d)}\left[\Delta a_{i}+(1-(n-1) d) \Delta c-m_{2}+K_{2}\right] & \text { if } \quad \frac{\sum_{i=1}^{n} \Delta a_{i}}{n[1-(n-1) d]}<\Delta c-\frac{m_{2}}{1-(n-1) d}\end{cases} \\
& \text { where } K_{1}=d \cdot \frac{\sum_{i=1}^{n}\left[\Delta a_{i}+(1-(n-1) d) \Delta c\right]+n m_{1}}{1-(n-1) d} \text { and } K_{2}=d \cdot \frac{\sum_{i=1}^{n}\left[\Delta a_{i}+(1-(n-1) d) \Delta c\right]-n m_{2}}{1-(n-1) d} ; i=1,2, \ldots, n
\end{aligned}
$$


Proposition 2 indicates how to correctly respond to demand and cost disruptions. The expression (8) in Proposition 2 implies that the optimal retail price $p_{i}{ }^{*}$ can be obtained by adding an adjustment to the original retail price $p_{i}^{0}$. It can also be found that the optimal retail price $p_{i}{ }^{*}$ given in (8) always increase linearly with $\Delta a_{i}$. In particular, when the market scale is increased $\left(\Delta a_{i}>0\right)$, the retailers will increase the price (in Case 1 and Case 2); when the market scale is decreased $\left(\Delta a_{i}<0\right)$, the retail price will be reduced (in Case 3 and Case 4). However, when the market scale has only changed insignificantly (in Case 2 and Case 4) $\Delta c-\frac{m_{2}}{1-(n-1) d}<\frac{\sum_{i=1}^{n} \Delta a_{i}}{n[1-(n-1) d]}<\Delta c+\frac{m_{1}}{1-(n-1) d}$, keeping the original product quantity $q_{i}^{0}$ is recommended, this shows that the original quantity strategy was resilient enough under limited market turbulence; however, when the market scale changes are large enough (in Case 1 and Case 3), adjusting the product quantities and retail prices becomes necessary.

\section{Coordination of supply chain after disruptions}

In a decentralised supply chain, all members will adjust their respective strategies and make decisions independently to maximise their individual profits after the demand and cost disruptions take place. The manufacturer will adjust the menu of revenue-sharing contracts including wholesale price $w_{i}$ and the retailers' shares of revenue $\phi_{i}$ generated from each unit, and the retailers will again select their favourite contract. Therefore, the previously derived coordination scheme (menu of contract) must be modified to achieve the maximum supply chain profit. Recall that the optimal retail prices $p^{*}=\left(p_{1}^{*}, p_{2}^{*}, \ldots, p_{n}^{*}\right)$ is given in Proposition 2 for this case. In the baseline case, the manufacturer can use a revenue-sharing contract to induce the retailer to adopt retail prices $p^{0}=\left(p_{1}^{0}, p_{2}^{0}, \ldots, p_{n}^{0}\right)$. When the market demand and production cost are disrupted, and decisionmaking is decentralised, a similar revenue-sharing contract can also be used to coordinate a supply chain.

When a decentralised supply chain adopts a revenue-sharing contract under demand and production cost disruption,

$$
\begin{aligned}
& \text { the retailer's profit is: } \\
& \overline{\Pi_{r i}}=\phi_{i} R_{i}-\left(w_{i}+c_{r i}\right) q_{i}=\phi_{i} p_{i}\left(a_{i}+\Delta a_{i}-p_{i}+d \sum_{j \neq i}^{n} p_{j}\right)-\left(w_{i}+c_{r i}\right)\left(a_{i}+\Delta a_{i}-p_{i}+d \sum_{j \neq i}^{n} p_{j}\right) \text { so the equilibrium }
\end{aligned}
$$

retail prices must meet the following first-order condition: $\frac{\partial \overline{\Pi_{r i}}}{\partial p_{i}}=\phi_{i}\left(a_{i}+\Delta a_{i}-2 p_{i}+d \sum_{j \neq i}^{n} p_{j}\right)+\left(w_{i}+c_{r i}\right)=0$. We find the equilibrium retail prices are $\overline{p_{i}^{D}}=\frac{w_{i}+c_{r i}+\phi_{i}\left(a_{i}+\Delta a_{i}+d \sum_{j \neq i}^{n} \overline{p_{j}^{D}}\right)}{2 \phi_{i}}$.

Now the manufacturer needs to see whether it is possible to choose appropriate parameters in the revenue-sharing contract so that the whole supply chain can be coordinated. Similar to Proposition 2, we differentiate the coordination problem into three cases based on the degree of disruptions. We know that the decentralised supply chain is coordinated when prices are equivalent to the optimal prices of the centralised channel. By solving $\overline{p_{i}^{D}}=p_{i}^{*}$, we derive the following - Proposition 3.

Proposition 3. For the decentralised case with both production cost and demand disruptions, the retailers select a most preferred contract from the menu of contracts $\left(w_{i}^{*}, \phi_{i}^{*}\right)$ offered by the manufacturer, the revenue-sharing contract can coordinate the supply chain and the profit allocation of the optimal supply chain profit can be realised if $\left(w_{i}^{*}, \phi_{i}^{*}\right)$ satisfies the following condition:

$$
\begin{gathered}
w_{i}^{*}=\phi_{i}^{*}\left[2 p_{i}^{*}-\left(a_{i}+\Delta a_{i}\right)-d \sum_{j \neq i}^{n} p_{j}^{*}\right]-c_{r i} \\
\max \left(\frac{c_{r i}+c_{s}+\Delta c}{2 p_{i}^{*}-\left(a_{i}+\Delta a_{i}\right)-d \sum_{j \neq i}^{n} p_{j}^{*}}, \frac{\left(\phi_{i}^{0} p_{i}^{0}-w_{i}^{0}-c_{r i}\right) q_{i r}^{0}}{\left(a_{i}+\Delta a_{i}-p_{i}^{*}+d \sum_{j \neq i}^{n} p_{j}^{*}\right) q_{i}^{*}}\right)<\phi_{i}^{*}<1, \\
\sum_{i=1}^{n}\left[\phi_{i}^{*}\left(p_{i}^{*}-\left(a_{i}+\Delta a_{i}\right)-d \sum_{j \neq i}^{n} p_{j}^{*}\right)+p_{i}^{*}-c_{r i}-c_{s}\right] q_{i}^{*}-\Delta^{*}>\prod_{s}^{0}, \quad i=1,2, \ldots, n .
\end{gathered}
$$


Proof: We know that if the decentralised supply chain system is coordinated by the revenue-sharing contract, the equilibrium retail prices in the decentralised supply chain are equivalent to the optimal retail price in the centralised supply chain, that is to say, $\overline{p_{i}^{D}}=p_{i}^{*}$. Solving the equations with respect to $w_{i}^{*}$ and $\phi_{i}^{*}$, we have

$$
w_{i}^{*}=\phi_{i}^{*}\left[2 p_{i}^{*}-\left(a_{i}+\Delta a_{i}\right)-d \sum_{j \neq i}^{n} p_{j}^{*}\right]-c_{r i} .
$$

Because $0<\phi_{i}^{*}<1$ and $w_{i}^{*}>c_{s}+\Delta c$, we have $\frac{c_{r i}+c_{s}+\Delta c}{2 p_{i}^{*}-\left(a_{i}+\Delta a_{i}\right)-d \sum_{j \neq i}^{n} p_{j}^{*}}<\phi_{i}^{*}<1$.

Then we have the profits of the partners with a new revenue-sharing contact under disruptions:

$$
\begin{gathered}
\prod_{r i}^{*}=\left(\phi_{i}^{*} p_{i}^{*}-w_{i}^{*}-c_{r i}\right) q_{i}^{*} \\
\prod_{s}^{*}=\sum_{i=1}^{n}\left(\left(1-\phi_{i}^{*}\right) p_{i}^{*}+w_{i}^{*}-c_{s}\right) q_{i}^{*}-\Delta^{*}
\end{gathered}
$$

Where $\Delta^{*}=m_{1} \cdot\left(\sum_{i=1}^{n} q_{i}^{*}-\sum_{i=1}^{n} q_{i}^{0}\right)^{+}+m_{2} \cdot\left(\sum_{i=1}^{n} q_{i}^{0}-\sum_{i=1}^{n} q_{i}^{*}\right)^{+}$

$$
q_{i}^{*}=a_{i}+\Delta a_{i}-p_{i}^{*}+d \sum_{i=1}^{n} p_{j}^{*} .
$$

Similarly, the profits of the partners with the original revenue-sharing contract under disruptions can be listed as follows:

$$
\begin{gathered}
\prod_{r i}^{0}=\left(\phi_{i}^{0} p_{i}^{0}-w_{i}^{0}-c_{r i}\right) q_{i r}^{0} \\
\prod_{s}^{0}=\sum_{i=1}^{n}\left(\left(1-\phi_{i}^{0}\right) p_{i}^{0}+w_{i}^{0}-c_{s}\right) q_{i r}^{0}-\Delta^{0} \\
\text { where } \Delta^{0}=m_{1} \cdot\left(\sum_{i=1}^{n} q_{i r}^{0}-\sum_{i=1}^{n} q_{i}^{0}\right)^{+}+m_{2} \cdot\left(\sum_{i=1}^{n} q_{i}^{0}-\sum_{i=1}^{n} q_{i r}^{0}\right)^{+} \\
q_{i r}^{0}=a_{i}+\Delta a_{i}-p_{i}^{0}+d \sum_{i=1}^{n} p_{j}^{0} .
\end{gathered}
$$

And the new revenue-sharing contracts are acceptable to the chain partners only if $\prod_{r i}^{*}>\prod_{r i}^{0}$ and $\prod_{s}^{*}>\prod_{s}^{0}$, so the following conditions should be satisfied:

$$
\begin{gathered}
\phi_{i}^{*}>\frac{\left(\phi_{i}^{0} p_{i}^{0}-w_{i}^{0}-c_{r i}\right) q_{i r}^{0}}{\left(a_{i}+\Delta a_{i}-p_{i}^{*}+d \sum_{j \neq i}^{n} p_{j}^{*}\right) q_{i}^{*}} \\
\sum_{i=1}^{n}\left[\phi_{i}^{*}\left(p_{i}^{*}-\left(a_{i}+\Delta a_{i}\right)-d \sum_{j \neq i}^{n} p_{j}^{*}\right)+p_{i}^{*}-c_{r i}-c_{s}\right] q_{i}^{*}-\Delta^{*}>\prod_{s}^{0}
\end{gathered}
$$

Furthermore, the following results hold: if $\Delta a_{i}=0$ and $\Delta c=0$, then $m_{1}=m_{2}=0$, and the whole supply chain system profit is simplified $\overline{\Pi_{T}}(q)=\Pi_{T}(q)=\sum_{i=1}^{n}\left[R_{i}(q)-c_{i} q_{i}\right]$, so the optimal retailer's price and wholesale price equal, respectively, $p_{i}^{*}=p_{i}^{0}$, and $w_{i}^{*}=\phi_{i}^{0}\left(2 p_{i}^{0}-a_{i}-d \sum_{j \neq i}^{n} p_{j}^{0}\right)-c_{r i}=w_{i}^{0}$. Consequently, the revenue-sharing contract $\left(w_{i}^{*}, \phi_{i}^{*}\right)$ can also realise supply chain coordination. In short, the improved revenue-sharing contract has anti-disruptions ability; the above results are consistent with that of the work by Cachon and Lariviere (2005). 
From Propositions 2 and 3, we find that when the cost and demand disruptions happen simultaneously and the degree of disruptions are within certain ranges $\left(\Delta c-\frac{m_{2}}{1-(n-1) d}<\frac{\sum_{i=1}^{n} \Delta a_{i}}{n[1-(n-1) d]}<\Delta c+\frac{m_{1}}{1-(n-1) d}\right)$, the production quantity need not be changed, while the retail prices and the revenue-sharing fraction for the retailers should be changed; if the degree of disruption exceeds certain ranges, both the production quantity, retail prices and the revenue-sharing fractions should be changed for the coordination necessary for the supply chain.

\section{Numerical examples}

In this section, we present some examples to analyse the effects of the demand and cost disruptions on the coordination mechanism. In particular, we are interested in the effect of the disruption management after various demand and cost changes. Knowing the demand and cost changes, the manufacturer will adopt an appropriate new revenue-sharing contract to recoordinate the supply chain (we called it the new policy). Conversely, if the manufacturer is unaware of the demand and cost changes and cannot react to the demand and cost disruptions in a timely manner, the retailers will keep the pre-assumed retail prices without changes and have the freedom to make new orders according to the real market (we called it the original policy). For these two cases, we compare the relative parameters of revenue-sharing contracts and analyse the profit difference from the perspective of partners and the whole supply chain. Without loss of generality, we consider a supply chain system consists of a manufacturer and three retailers, the demand-price function is $q_{i}=a_{i}-p_{i}+d \sum_{j \neq i} p_{j},(i=1-3)$.

We first consider the revenue-sharing contract without disruptions and analyse the following examples with parameters: $a_{1}=a_{2}=a_{3}=20, c_{r 1}=1, c_{r 2}=2, c_{r 3}=3, c_{s}=6, d=0.4$. In the baseline case, given the above values, from Proposition 1, we can obtain the retail prices of retailer 1 , retailer 2 , and retailer 3 , respectively, $p_{1}^{0}=53.5, p_{2}^{0}=54$, and $p_{3}^{0}=54.5$. The corresponding ordering quantities are $q_{1}^{0}=9.9, q_{2}^{0}=9.2$, and $q_{3}^{0}=8.5$. The optimal production quantity of manufacturer is 27.6, the profits for channel 1, channel 2, and channel 3 are $\Pi_{1}=460.35, \Pi_{2}=423.2$, and $\Pi_{3}=386.75$, respectively, the total profit of supply chain is 1270.3 . Based on Proposition 1, we can obtain the revenue-sharing contract for assuring the coordination of the supply chain, and the revenue-sharing contract parameters satisfy the following conditions.

$w_{1}=43.6 \cdot \phi_{1}-1, \quad \phi_{1} \in(0.1606,0.5596) ; \quad w_{2}=44.8 \cdot \phi_{2}-2, \quad \phi_{2} \in(0.1786,0.5556) ; \quad w_{3}=46 \cdot \phi_{2}-3$, $\phi_{3} \in(0.1987,0.5515)$. We can illustrate the revenue-sharing contracts, which are depicted in Figures $1-3$. From Figures $1-3$, we find that only the value of $w_{i}$ and $\phi_{i}$ along the continuous line can make the supply coordinated.

If, further assuming that the manufacturer and retailers agree to share the total supply chain profit at a ratio of 6:4 under the assumption of symmetric information, where $\phi_{1}=\phi_{2}=\phi_{3}=0.4$, then from Proposition 1, we can obtain the wholesale $w_{1}=16.44, w_{2}=15.92, w_{3}=15.4$. From Equation (1) in Proposition 1 , we can obtain the retailers'

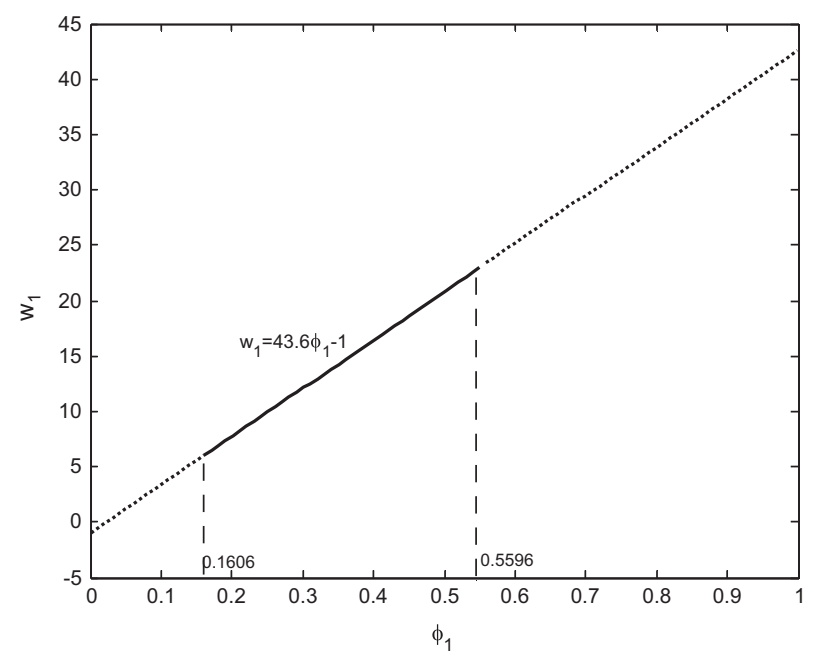

Figure 1. The revenue-sharing contract: the wholesale price $w_{1}$ vs. revenue share $\phi_{1}$. 


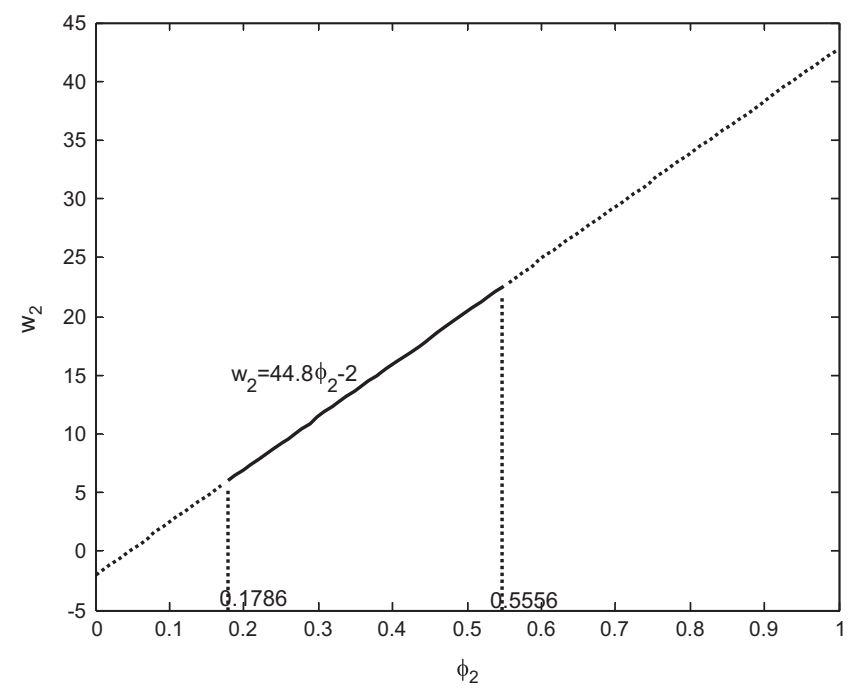

Figure 2. The revenue-sharing contract: the wholesale price $w_{2}$ vs. revenue share $\phi_{2}$.

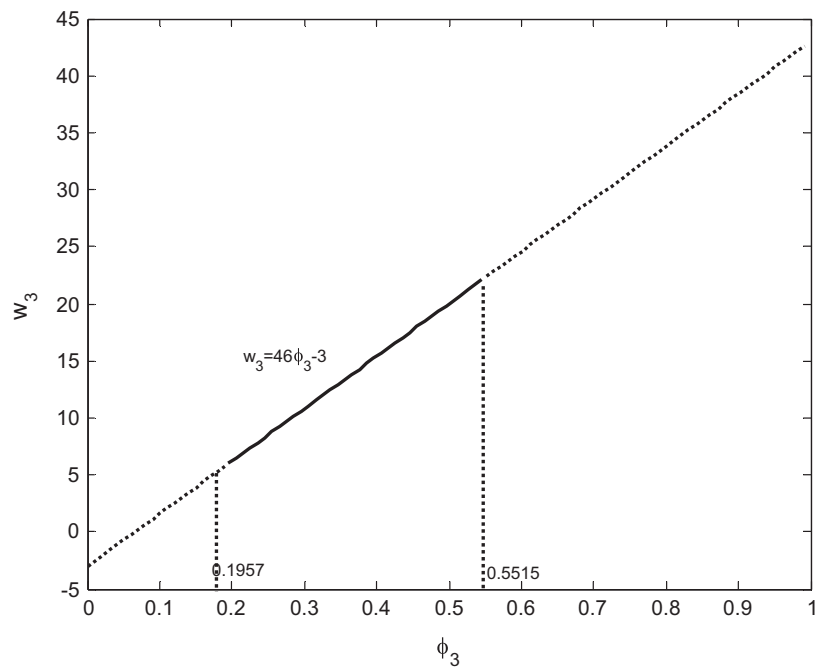

Figure 3. The revenue-sharing contract: the wholesale price $w_{3}$ vs. revenue share $\phi_{3}$.

Table 1. The optimal retail price and quantity under different disruptions.

\begin{tabular}{|c|c|c|c|c|c|}
\hline Cases & & 1 & 2 & 3 & 4 \\
\hline$\Delta a_{1}$ & & -1 & -1 & 1 & 1 \\
\hline$\Delta a_{2}$ & & -1 & -1 & 1 & 1 \\
\hline$\Delta a_{3}$ & & -1 & -1 & 1 & 1 \\
\hline$\Delta c$ & & -1.5 & 1.5 & -1.5 & 1.5 \\
\hline \multirow[t]{2}{*}{ Production quantity } & Original policy & 24.6 & 24.6 & 30.6 & 30.6 \\
\hline & New policy & 27.6 & 27.15 & 28.05 & 27.6 \\
\hline \multirow{2}{*}{ Retailer 1 (quantity, price) } & Original policy & $8.9, \mathbf{5 3 . 5}$ & $8.9, \mathbf{5 3 . 5}$ & $10.9, \mathbf{5 3 . 5}$ & $10.9, \mathbf{5 3 . 5}$ \\
\hline & New policy & 9.9, 48.5 & $9.75,49.25$ & $10.05,57.75$ & $\mathbf{9 . 9}, 58.5$ \\
\hline \multirow[t]{2}{*}{ Retailer 2 (quantity, price) } & Original policy & $8.2, \mathbf{5 4}$ & $8.2, \mathbf{5 4}$ & $10.2, \mathbf{5 4}$ & $10.2,54$ \\
\hline & New policy & $9.2,49.0$ & $9.05,49.75$ & $9.35,58.25$ & $9.2,59$ \\
\hline \multirow[t]{2}{*}{ Retailer 3 (quantity, price) } & Original policy & $7.5, \mathbf{5 4 . 5}$ & $7.5, \mathbf{5 4 . 5}$ & $9.5, \mathbf{5 4 . 5}$ & $9.5,54.5$ \\
\hline & New policy & $\mathbf{8 . 5}, 49.5$ & $8.35,50.25$ & $8.65,58.75$ & $8.5,59.5$ \\
\hline
\end{tabular}


Table 2. The optimal wholesale price under different disruptions.

\begin{tabular}{|c|c|c|c|c|c|}
\hline Cases & & 1 & 2 & 3 & 4 \\
\hline$\Delta a_{1}$ & & -1 & -1 & 1 & 1 \\
\hline$\Delta a_{2}$ & & -1 & -1 & 1 & 1 \\
\hline$\Delta a_{3}$ & & -1 & -1 & 1 & 1 \\
\hline$\Delta c$ & & -1.5 & 1.5 & -1.5 & 1.5 \\
\hline \multirow[t]{2}{*}{$w_{1}$} & Original policy & 16.84 & 16.84 & 16.04 & 16.04 \\
\hline & New policy & 14.44 & 14.8 & 18.08 & 18.44 \\
\hline \multirow[t]{2}{*}{$w_{2}$} & Original policy & 16.32 & 16.32 & 15.52 & 15.52 \\
\hline & New policy & 13.92 & 14.28 & 17.56 & 17.92 \\
\hline \multirow[t]{2}{*}{$w_{3}$} & Original policy & 15.8 & 15.8 & 15 & 15 \\
\hline & New policy & 13.4 & 13.76 & 17.04 & 17.4 \\
\hline
\end{tabular}

Table 3. The optimal location profit under different disruptions.

\begin{tabular}{|c|c|c|c|c|c|}
\hline Cases & & 1 & 2 & 3 & 4 \\
\hline$\Delta a_{1}$ & & -1 & -1 & 1 & 1 \\
\hline$\Delta a_{2}$ & & -1 & -1 & 1 & 1 \\
\hline$\Delta a_{3}$ & & -1 & -1 & 1 & 1 \\
\hline$\Delta c$ & & -1.5 & 1.5 & -1.5 & 1.5 \\
\hline \multirow{2}{*}{ Channel 1's profit } & Original policy & 426.2 & 399.5 & 522.2 & 489.5 \\
\hline & New policy & 425.7 & 397.1625 & 524.9625 & 495 \\
\hline \multirow[t]{2}{*}{ Channel 2's profit } & Original policy & 388.5 & 363.9 & 483.5 & 452.9 \\
\hline & New policy & 391 & 364.1125 & 483.7125 & 455.4 \\
\hline \multirow[t]{2}{*}{ Channel 3's profit } & Original policy & 351.5 & 329 & 445.5 & 417 \\
\hline & New policy & 357 & 331.7625 & 443.1625 & 416.5 \\
\hline
\end{tabular}

Table 4. The effects of different disruptions on partners and total profits.

\begin{tabular}{|c|c|c|c|c|c|c|c|c|c|c|c|c|c|c|}
\hline \multirow[b]{2}{*}{ Cases } & \multirow[b]{2}{*}{$\Delta a_{1}$} & \multirow[b]{2}{*}{$\Delta a_{2}$} & \multirow[b]{2}{*}{$\Delta a_{3}$} & \multirow[b]{2}{*}{$\Delta c$} & \multicolumn{2}{|c|}{ Supplier profit } & \multicolumn{2}{|c|}{ Retailer 1's profit } & \multicolumn{2}{|c|}{ Retailer 2's profit } & \multicolumn{2}{|c|}{ Retailer 3's profit } & \multicolumn{2}{|c|}{$\begin{array}{l}\text { Total profit of } \\
\text { supply chain } \\
\text { system }\end{array}$} \\
\hline & & & & & $\begin{array}{c}\text { Original } \\
\text { policy }\end{array}$ & $\begin{array}{l}\text { New } \\
\text { policy }\end{array}$ & $\begin{array}{c}\text { Original } \\
\text { policy }\end{array}$ & $\begin{array}{l}\text { New } \\
\text { policy }\end{array}$ & $\begin{array}{c}\text { Original } \\
\text { policy }\end{array}$ & $\begin{array}{l}\text { New } \\
\text { policy }\end{array}$ & $\begin{array}{c}\text { Original } \\
\text { policy }\end{array}$ & $\begin{array}{l}\text { New } \\
\text { policy }\end{array}$ & $\begin{array}{c}\text { Original } \\
\text { policy }\end{array}$ & $\begin{array}{l}\text { New } \\
\text { policy }\end{array}$ \\
\hline 1 & -1 & -1 & -1 & -1.5 & 1085.1 & 1071.7 & 31.684 & 39.2040 & 26.896 & 33.856 & 22.5 & 28.9 & 1166.2 & 1173.7 \\
\hline 2 & -1 & -1 & -1 & 1.5 & 1011.3 & 994.4 & 31.684 & 38.025 & 26.896 & 32.761 & 22.5 & 27.889 & 1092.4 & 1093 \\
\hline 3 & 1 & 1 & 1 & -1.5 & 1326 & 1346.5 & 47.524 & 40.4010 & 41.616 & 34.969 & 36.1 & 29.929 & 1451.2 & 1451.8 \\
\hline 4 & 1 & 1 & 1 & 1.5 & 1234.2 & 1264.9 & 47.524 & 39.2 & 41.616 & 33.856 & 36.1 & 28.9 & 1359.4 & 1366.9 \\
\hline
\end{tabular}

optimal profits $\Pi_{r 1}=39.2040, \Pi_{r 2}=33.8560$ and $\Pi_{r 3}=28.9000$, respectively. The optimal profits of the manufacturer and the supply chain are $\Pi_{s}=1168.3$ and $\Pi_{T}=1270.3$, respectively. As a result, it is clear that the revenue-sharing contract can effectively coordinate the supply chain.

Furthermore, we consider and analyse the following example with parameters: $a_{1}=a_{2}=a_{3}=20, c_{r 1}=1, c_{r 2}=2$, $c_{r 3}=3, d=0.4 \Delta a_{1}=\{-1,1\}, \Delta a_{2}=\{-1,1\}, \Delta a_{3}=\{-1,1\}, \Delta c=\{-1.5,1.5\}, m_{1}=m_{2}=1$. In general, the directions of the market demand or cost disruptions faced by retailers are very much in the same direction. So, we consider the cases that retailers are facing similar disruptions in market demands or production costs, the similar cases were discussed in (Xiao and Qi 2008). We obtained the retail prices and wholesale prices under the original policy and the new policy, which are reported, respectively, in Tables 1 and 2. In order to illustrate the efficiency of the revenue-sharing contracts, the associated parameters, including location profits are depicted in Table 3 . The different disruptions have effects on partners and total profits, which are given in Table 4. 
In general, when there is only production cost disruption, the optimal production quantities and production cost disruptions are negatively correlated, that is the higher the production cost is, the smaller the optimal production quantity will be, as the optimal retail price increases, and vice versa (Xu, Qi, and Yu 2006). When there is only demand disruption, the optimal production quantities and demand disruptions are positively correlated, that is the larger the demand is, the higher the optimal production quantity will be, as the optimal retail price increases, vice versa (Qi, Bard, and $\mathrm{Yu}$ 2004). However, from Proposition 2 in Equation (8), we know that the optimal retail price is an increasing function of the incremental amount of demand when the production cost and demand simultaneously disrupted.

From Table 1, we found that the retail prices are unchanged when one adopts the original policy. The optimal production quantities (or the ordering quantities) and demand disruptions are positively correlated, and the optimal production quantities are independent of the cost disruptions. However, in a new policy, the changes of the retail price and ordering quantity are more complicated. When the market size is changed slightly (the first case and the fourth case in Table 1), keeping the original production plan but adjusting the retail prices should be sufficient to deal with the disruptions of demand and cost of productions, which demonstrates that the original plan has certain degree of robustness. When the market size is changed significantly (the second case and the third case in Table 1), it requires the production plan (in terms of the quantity of products) as well as the retail price to be adjusted in order to settle disruptions of demand and cost of productions. The main reasons are as follows: when the demand and production costs change in the same direction and within a robust region (the first case and the fourth case in Table 1), the demand and the cost disruption will interact with each other; thus, there is a mutual constraint relationship between demand interruption and cost production. The manufacturer does not need to adjust the production plan $\left(q_{i}^{*}=q_{i}^{0}\right)$, and all the retailers' optimal ordering quantities are equal to their optimal ordering quantities under normal circumstances, that is $q_{1}^{*}=q_{1}^{0}=9.9$, $q_{2}^{*}=q_{2}^{0}=9.2, q_{3}^{*}=q_{3}^{0}=8.5$, and the optimal production quantity of manufacturer is 27.6 , which shows that the supply chain achieves optimal profits. However, all the retailers need to adjust their retail prices to deal with the demand and cost disruptions. Additionally, the demand and production cost disruptions mutually affect and restrict each other, that is the adverse effect of one disrupted event is eliminated by another disrupted event, and therefore, the total supply chain profit remains stable, demonstrating that the revenue-sharing contract's robustness. The supply chain obtains a higher profit by changing the retail prices in these cases.

From Tables 1 and 2, it can be seen that when the market demand and production cost are disrupted in different directions, from the second case, the market demand decreases and production cost increases simultaneously, the supplier responds to the disruption in both the original strategy and the new strategy by decreasing the production quantity from the original optimal production quantity: 27.6 to 24.6 and 27.15, respectively. From the third case, the market demand increases and production cost decreases simultaneously, the supplier responds to the disruption by increasing the production quantity compared with the original optimal production quantity: 27.6. The optimal production quantity, retail prices, and coordination strategy should be adjusted in response to the disruptions in these two above cases. From Table 4, we can see that the retail prices bring in higher total profit in the new strategy than that in the old strategy, which adopts fixed retail prices.

From Table 2, we found the wholesale price is independent of the cost disruptions when one adopts the original policy. The reasons are the retail prices are unchanged (from Table 1, we known that $p_{1}^{0}=53.5, p_{2}^{0}=54$ and $p_{3}^{0}=54.5$ ) and the production quantities (ordering quantities) are independent of the cost disruptions. Moreover, from Table 4, we found the retailer's profit is independent of the cost disruptions when one adopts the original policy because the retail prices and wholesale prices do not change and the manufacturer bears fully the production deviation cost caused by the disruptions.

From Table 4, we find that the effect of disruption management on the partners' profitability can be significant, even when the effect on the channel profit is fairly small. According to Tables 3 and 4, the total supply chain system's profits of the new production plan are more than those of keeping the original retail prices. Tables 3 and 4 also indicate that the improved revenue-sharing contract can cope with demand and cost disruptions.

\section{Conclusion}

In this study, a mathematic model-based Stacklberg game theory has been proposed for analysing the process of coordinating of a supply chain under disruptions of market demands and production costs as well as for providing optimised decisions-making. We introduced optimised strategies for the coordination of revenue-sharing contracts between a manufacturer and the retailers of a supply chain under demand and cost simultaneous disruptions.

In a centralised system, we proposed an optimised strategy model; optimised solutions for price and quantity are obtained through resolving Karush-Kuhn-Tucker (KKT) condition. When the market size is changed slightly, keeping the original production plan but adjusting the retail prices should be sufficient to deal with the disruptions of demand and cost of productions, which demonstrates that the original plan has certain degree of robustness. When the market 
size is changed significantly, it requires the production plan (in terms of the quantity of products) as well as the retail price to be adjusted in order to settle disruptions of demand and cost of productions.

In a decentralised system, a modified revenue-sharing contract is needed when demand and cost interruptions occur, when no disruption exists the basic model will be applied (Proposition 1). To resolve the problem of coordinating a supply chain after disruptions on demands and costs from marketing is a complex and dynamic challenge, one way to support decision-making is to develop a mechanism that works in an interactive manner, thus more realistic solutions based on the scenarios can be provided, this is the direction we are currently working on.

\section{Acknowledgements}

We thank the associated editor and the anonymous referees for their excellent and constructive comments, which led to significant improvements in this paper. This research is supported in part by: (i) the National Natural Science Foundation of China under Grants 71,001,035 and 70,925,006; (ii) the Program for New Century Excellent Talents in University under Grant NCET-13-0181.

\section{References}

Bernstein, F., and A. Federgruen. 2003. "Pricing and Replenishment Strategies in a Distribution System with Competing Retailers." Operations Research 51 (3): 409-426.

Cachon, G. 2003. "Supply Chain Coordinated with Contracts." In Handbooks in Operations Research and Management Science: Supply Chain Management, edited by Steve Graves and Tonde Kok, 1-30. Amsterdam: North Holland.

Cachon, G. P., and M. A. Lariviere. 2005. "Supply Chain Coordination with Revenue-Sharing Contracts: Strength and Limitations." Management Science 51 (1): 30-44.

Chen, Jing, Hui Zhang, and Ying Sun. 2012. "Implementing Coordination Contracts in a Manufacturer Stackelberg Dual-channel Supply Chain." Omega 40: 571-583.

Chen, Kebing, and Pin Zhuang. 2011. "Disruption Management for a Dominant Retailer with Constant Demand-stimulating Service Cost." Computers \& Industrial Engineering 61: 936-946.

Chen, Kebing, and Tiaojun Xiao. 2009. "Demand Disruption and Coordination of the Supply Chain With a Dominant Retailer." European Journal of Operational Research 197 (1): 225-234.

Clausen, J., J. Hansen, and J. Larsen. 2001. "Disruption Management.” OR/MS Today 28 (5): 40-43.

Dana Jr., J. D., and K. E. Spier. 2001. "Revenue Sharing and Vertical Control in the Video Rental Industry." Journal of Industrial Economics 49 (3): 223-245.

Friesz, Terry L., Ilsoo Lee, and Cheng-Chang Lin. 2011. "Competition and Disruption in a Dynamic Urban Supply Chain.” Transportation Research Part B 45: 1212-1231.

Gerchak, Y., and Y. Wang. 2004. "Revenue-sharing vs Wholesale-price Contracts in Assembly Systems with Random Demand.” Production and Operation Management 13 (1): 23-33.

Giannoccaro, I., and P. Pontrandolfo. 2004. "Supply Chain Coordination by Revenue Sharing Contracts." International Journal of Production Economics 89 (2): 131-139.

Hou, J., Amy Z. Zeng, and Lindu Zhao. 2010. "Coordination with a Backup Supplier Through Buy-back Contract under Supply Disruption." Transportation Research Part E 46 (6): 881-895.

Huang, Chongchao, Gang Yu, and Wang Song. 2006. "Disruption Management For Supply Chain Coordination With Exponential Demand Function.” Acta Mathematica Scientia 26B (4): 655-669.

Huang, Song, Chao Yang, and Xi Zhang. 2012. "Pricing and Production Decisions in Dual-channel Supply Chains with Demand Disruptions." Computers \& Industrial Engineering 62: 70-83.

Kebing, Chen, Gao Chengxiu, and Wang Yan. 2007. "Revenue-sharing Contract to Coordinate Independent Participants within the Supply Chain." Journal of Systems Engineering and Electronics 18 (3): 520-526.

Lei, Dong, Jianbin Li, and Zhixue Liu. 2012. "Supply Chain Contracts under Demand and Cost Disruptions with Asymmetric Information.” International Journal of Production Economics 139 (1): 116-126.

Li, Jian, Shouyang Wang, and T. C. E. Cheng. 2010. "Competition and Cooperation in a Single-retailer Two-supplier Supply Chain with Supply Disruption.” International Journal of Production Economics 124: 137-150.

Li, Sijie, and Zhongsheng Hua. 2008. "A Note on Channel Performance Under Consignment Contract With Revenue Sharing." European Journal of Operational Research 184: 793-796.

Pasternack, B. A. 1985. "Optimal Pricing and Returns Policies for Perishable Commodities.” Marketing Science 4 (2): $166-176$.

Qi, X. T., J. Bard, and G. Yu. 2004. "Supply Chain Coordination with Demand Disruptions.” Omega 32 (4): $301-312$.

Wang, Y., L. Jiang, and Z. Shen. 2004. "Channel Performance Under Consignment Contract with Revenue Sharing." Management Science 50 (1): 34-47.

Weng, Z. K. 2004. "Coordinating Order Quantities Between the Manufacturer and the Buyer: A Generalized Newsvendor Model." European Journal of Operational Research 156: 148-161. 
Wu, Yifan, Ming Dong, Wei Tang, and F. Frank Chen. 2010. "Performance Analysis of Serial Supply Chain Networks Considering System Disruptions." Journal of Production Planning and Control 21 (8): 774-793.

Xiao, Tiaojun, and Xiangtong Qi. 2008. "Price Competition, Cost and Demand Disruptions and Coordination of a Supply Chain with One Manufacturer and Two Competing Retailers." International Journal of Management Science 36 (5): 741-753.

Xiao, T. J., and G. Yu. 2006. "Supply Chain Disruption Management and the Evolution of Retailers' Behaviors in the QuantitySetting Duopoly Situation with Homogeneous Goods.” European Journal of Operational Research 173 (2): 648-668.

Xiao, T. J., G. Yu, and Z. H. Sheng. 2005. "Coordination of a Supply Chain with One-manufacturer and Two-retailers Under Demand Promotion and Disruption Management Decisions." Annals of Operations Research 135 (1): 87-109.

Xu, M. H., X. T. Qi, and G. Yu. 2006. "Coordinating Dyadic Supply Chains when Production Costs are Disrupted.” IIE Transactions 38 (9): 765-775.

Yao, Z., Stephen C. H. Leung, and K. K. Lai. 2008. "Manufacturer's Revenue-sharing Contract and Retail Competition.” European Journal of Operational Research 186: 637-651.

Yu, Gang, and Xiangtong Qi. 2004. Disruption Management: Framework, Models and Application. Singapore: World Scientific.

Yu, Haisheng, Amy Z. Zeng, and Lindu Zhao. 2009. "Single or Dual Sourcing: Decision-making in the Presence of Supply Chain Disruption Risks." Omega 37: 788-800.

Zegordi, Seyed Hessameddin, and Hoda Davarzani. 2012. "Developing a Supply Chain Disruption Analysis Model: Application of Colored Petri-nets." Expert Systems with Applications 39: 2102-2111.

Zou, X., S. Pokharel, and R. Piplani. 2004. "Channel Coordination in an Assembly System Facing Uncertain Demand with Synchronized Processing Time and Delivery Quantity.” International Journal of Production Research 42 (22): $4673-4689$. 